\title{
A CONTRIBUTION TO THE SURGERY OF THE HYPOPHYSIS.
}

Br Dr. JLles Broeckatert,

Ghent.

\author{
Translater b? Chichele Nounse, F.R.C.S.Edn. ${ }^{1}$
}

THE surgery of the hypophysis cerebri, although a derelopment of quite recent date, has been, from its very commencement, a sulject of keen interest to rhinologists, to whom the idea of operating on the pituitary gland by simple methods, carried ont through the natural passages, immediately occurrer.

In opposition to surgical procedures through artificial routes. Citelli, West, and Hirsch have accordingly proposed rhinologica methods which, according to their anthors, have a real superiorit! orer those of general surgeons.

I desired to ascertain for myself the comparative value of each of these procedures; and, with this intention, I performed a certai number of operative cxercises, the result of which is here mad. known.

\section{Anatomical Facts.}

The hypophysis or pituitary gland is an organ attached to the lower surface of the cerebrum by a narrow pedicle, the stem of thr hypophysis, and enclosed in the sella turcica between the lamini of the sphenoid and the two cavernous sinuses. It occupies: fibrous compartment, the roof of which is composed of a diaphragr or fold of dura mater, known under the name of the pituitar? tentorium; in the anterior and lower part of the dural investmen a venous plexus, connected with the anterior coronary sinus, is me: with.

The gland is composed of an anterior lobe, by far the larger" the two, called the hypophysis proper, and of a posterior lobe aldescribed under the name of the nerrous or cerebral lobe. 'Th first is developed from a diverticulum of the superior wall of th primitive buccal cavity; the second is a protrusion of the floor " the middle rentricle from the inferior surface of the brain (Charpy).

The sella turcica, upon which the pituitary gland rests, normal: forms a part of the superior wall of the sphenoidal sinus; and $\cdots$ from a surgical point of view, one of its most important relationThe thickness of this wall is usually very slight, and in certam cases there are even actual dehiscences at this point, which allus

1 From La Presse Oto-Laryng. Bel!le. July, 1912. 
t perfect cohesion of the mucous lining of the sinus and the dural investment.

When the sphenoidal sinus is very large, the convex base of he sella turcica often forms a prominence in the cavity of the inus. It is at the back, on a line with its sloping part, that the usseous vault of the sinus is in relation with the pituitary gland; n its anterior part, the superior wall of the sphenoidal cavity is in elation with the inferior surface of the first frontal convolution.

However, as Levinger has observed, and as I have been able " convince myself in the course of my researches upon the cadaver, the position of the sella turcica in relation to the sphenoidal sinuses is most inconstant. 'Ihus, on a preparation in my possession, the irpophysis is in the centre of the root of the sinus, which is proinged far downwards and backwards.

At other times, as I have observed in several specimens, the whenoidal sinus is smaller than usual, and is separated from the -ella turcica by a very thick bony wall.

In certain cases the sphenoidal sinus is found to lie very forward, and the sella turcica is lodged in the thickness of the bone, behind the sinus cavity.

Finally, I must mention the relative frequency of a large "thmoido-sphenoidal cell, which is found between the sphenoidal mus and the base of the cranium. In such cases, as Furet has bserved, the roof of the sinus is no longer in relation with the ranial cavity, but is formed by the floor of this intruding cell.

It must be borne in mind also that the sphenoidal sinus is iivided in two by a septum, which is never, so to speak, situated in the median line. The most raried arrangements are met with etre, so that it may be stated with Jacob that "inequality is the mle." These two unequal cavities, of an irregularly cuboid form, wre situated between the nasal fossa and the basilar process in one direction, and between the base of the cranimm and the pharynx in the other. Their anterior wall forms the remotest part of the s.sal vant, and is a prolongation from the cribriform plate of the "thmoid. Its direction is slightly inclined from above downwards, ind from before backwards, and it is continuous with the inferior wall, of which the external surface corresponds to the nasotharyngeal region.

The anterior wall presents a free surface in the nasal fossa, on tach side of the median line, and, external to this, a rough surface, lorger still, hidden by the posterior extremity of the ethmoidal lahyrinth. 


\section{Operative Methods.}

The hypophysis can be approached either by the intra-cranial route or by the extra-cranial route through the sphenoidal sinus; hence there are two methods of hypophysectomy-intra-cranial hypophysectomy and trans-sphenoidal hypophysectomy.

I will not dwell upon the intra-cranial operation, which can be performed by the temporal or by the frontal route. This method is open to so much serious criticism that, in the immense majority of cases, if not invariably, the extra-cranial methods should be preferred as being much more logical and practicable.

Giordano was the first, in 1897 , to recommend removal of the hypophysis through the trans-sphenoidal route, by directly attacking the floor of the sella turcica. However, the first operation of this kind was not performed until much later, when Schloffer, in March, 1907, successfully removed an adenoma of the hypophysis by this method.

'The most diverse routes have been suggested in order to reach the sphenoidal sinus. Some of these have no practical interest. and seem hardly applicable to the living subject. We may thu dismiss the pharyngeal route, proposed by Loewe, and also the maxillary route. These cadaveric operations are undoubtedly to. mutilating, and may be resolutely set aside.

The palatine route, formerly proposed by König, and long made use of in physiological laboratories, was followed twice on the living subject by Durante and by Stewart and Ballance. It ia mode which attracted me from the outset of my exercises on the cadaver, and which I carried out as follows:

The velum of the palate, rendered tense by holding the urul: with a pair of forceps, is divided completely by a median incision. which is prolonged forward under the osseous palate half way $t$ the incisor teeth. By the aid of a raspatory the muco-periostem is then detached in two flaps, which must be carefully loosened at the posterior edge of the hard palate.

In order to keep apart the two halves of the divided velum, : thread is passed through each half of the uvula, and the end fixed outside the mouth.

The horizontal plate of the palate bones is then removed with bone-forceps. The posterior part of the septum remains t" be dealt with. A strong pair of gouge-forceps will serve to undermine the septum, and to cut away little by little the hard romer.

Then the sphenoidal sinus is opened with a gouge and mallet in 
the median line, from its antero-inferior aspect, by destroying the lifurcated edge of the vomer and the crest of the sphenoid.

The sphenoidal sinus being freely opened, the situation of the posterior and superior aspects of the sinus must be ascertained exactly, and the septum separating the two sinuses is taken away. The convexity of the floor of the sella turcica, near the posterior limit of the sinus, is then attacked with a narrow chisel.

The opening is enlarged in breadth to the extent of more than - ne centimetre, sufficient to permit the introduction of the forceps and curettes designed to remore the hypophysis or the tumour.

We must insist upon the necessity of opening the superior wall if the sinus exactly in the median line: all the landmarks should te carefully determined, and it is only when this has been done ander the control of artificial light that the operator will proceed with great delicacy to open the pituitary chamber.

Partsch has proposed, as a palatine route, a temporary displace. nent downwards of the whole of the bony palate. The same 'peration was undertaken by Löwe, who advised a combination of the "mporary downward displacement of the palate with decortication whe face. 'These procedures appear to me very inferior to that ihich has just been described, and even to those which frankly nake use of the nasal route.

The nasal route is that which so far has been preferred by "herators. Out of fifty-four hypophysectomies collected by Toupet, thirty-three were performed in this way. But in order (1) reach the sphenoidal sinus by this route, what varied procedures have heen suggested! All the modes of temporary rhinotomy ine had their partisans among gencral surgeons, whilst rhinolowists have set aside all the artificial routes in order to confine themselves exclusively to the natural passages.

\section{A. Methods by Artificial Routex.}

Access to the nasal fosse has been stuclied by the median wute, by the lateral route, by the superior route; and by the ufterior route.

Proust and Lecène consider that Ollier's rertical and bilateral "teotomy is the operation of choice. Schloffer, ron Eiselsbere, and others prefer the lateral reflection of the nose by the method if rou Bruns and Moure.

Besides these methods qenerally followed, allusion must be made to that of the American Kanavol, who turns the external unse upwards by a U-shaped incision: and to that of Dialti, who 
proposes a single dorsal incision dividing the nose from top to bottom in the median line, so that it can be opened in two flaps. Whatever may be the method adopted to gain access to the nasal fossa, it is completed by evacuation of their contents.

This important stage of the operation consists in resection of the ethmoid, of the septum, and of the inferior and middle turbinals. The whole of the upper part of the nose is thus completely clearer. Schloffer, ron Eiselsberg, Proust and others do not resect the nasal septum completely, but take care not to interfere with its posterior border, so as to leave intact the posterior orifices if the choane, and to respect the articulation of the vomer with the sphenoid.

Several operators follow the rhinotomy by the ablation of the anterior wall of the frontal sinus, so as to facilitate access to the higher part of the nasal cavity, and to get nearer to the sella turcica. I agree with Kocher, Goris and other's that this is an absolutely useless complication of the operation, which may very well be omitted.

When the rhinotomy has been performed by one of thene methods and hæmorrhage has been checked, the operator proceed.s to make a large opening into the sphenoidal sinus and to trephine the sella turcica.

The exact situation of the sphenoidal sinus is generally recopnised by the two openings by which it communicates with the nasal fossa. The anterior wall is then opened with the curette or the chisel, and the septum is destroyed with cutting forceps.

When all bleeding has ceased, and when the median line ha: been exactly localised, the sella turcica can be opened and the durn mater laid bare. In acromegaly and in cases of tumour of the hypophysis, the thinned wall often bulges into the siuus and can be opened by a stroke of the curette; at other times it is necessary to attack the postero-superior wall of the sinus with a gouge, "resting the handle," as Schloffer advises, " upon the lower edge of the nasal fossæ."

We need not dwell upon the later stages of the operation; the incision of the dura mater, and the extirpation of the hypophysic or the ablation of the tumour. Here the operator must be guided by the peculiarities of each case, and it must not be lost sight of that many tumours of the hypophysis are really cysts which only require to be punctured or incised.

For the removal of a diseased hypophysis or of a tumour a dull curette with a malleable handle is to be preferred. 


\section{B. Methods by Natural Routes.}

Hirsch, West and Citelli have sought to reach the hypophysis hy openiug the sphenoidal sinus through the endo-nasal route. Their methods are based on the same principle, that of opening the -phenoidal sinus and the sella turcica in the median line without a preliminary rhinotomy.

(1) Hirsch's Method.-To Hirsch belongs the merit of having performed the first hypophysectomy by the endo-nasal route. The !rocedure adopted by the Viennese operator was that iudicated by Hajek for making a free opening into the sphenoidal sinus. In pite of the successful result of this operation Hirsch has since given up the method he then followed, which required several sittings and which had serious drawbacks.

Since then, Hirsch proposed and has performed several times he following operation, which was suggested to him by that of Kocher. The latter opened the superior osseous part of the nose iike a double door, by a $\mathbf{Y}$-shaped incision, of which the vertical rart followed the dorsal line, and the two oblique branches divided the nose below the nasal bones. He then performed a submucous esection of the whole of the nasal skeleton, and opened the - whenoidal sinus and the sella turcica between the two blades of a trong speculum, which separated the two layers of mucous memirane and crushed the lateral masses of the ethmoid.

Hirsch practises, under local anæsthesia, submucous resection it the whole of the nasal septum, very nearly according to Killian's Iassic operation: thus he removes the quadrangular cartilage, the verpendicular plate of the ethmoid, the vomer, and the crest of the sphenoid. By carefully detaching the mucous membrane of the anterior wall of the sphenoid, he brings clearly into view the two sphenoidal ostia. The middle turbinals are removed if neces"iry ; after which, through the tunnel obtained by separating the wo layers of the mucous membrane of the septum by means of a Killian's speculum, he opens both sphenoidal sinuses in the median the with a gouge, destroys their septum with cutting forceps, and hreaks through the wall of the sella turcica.

(2) West's Method.- The technique that West has described in the Archiv für Laryngologie is the following:

(a) Resection, on one side, of the middle turbinal and of a more or less extensive part of the inferior turbinal, so as to expose the anterior wall of the sphenoidal sinus. Ablation of the anterior will of the sphenoidal sinus. 
(b) The same proceeding on the other side.

(c) The formation, by the aid of Jansen's forceps, of a long rectangular window in the nasal septum. This opening extends obliquely from behind forwards and from above downwards, from the antero-inferior surface of the body of the sphenoid nearly to the columella.

(d) Resection of the septum between the sphenoidal sinuses, and opening the base of the sella turcica in the median line.

(3) Citelli's Method.-At the same time that West's work appeared Citelli made known his own method of operating, which is similar to that of his American confrère in nearly every point.

In a first sénce, Citelli removes the anterior third or half of the inferior turbinal, the middle turbinal, and the inferior ethmoidal cells of one side, in such a way as to expose to view nearly the whole of the anterior wall of the corresponding sphenoidal sinus and the anterior part of its inferior wall. Then, with a sharppointed knife, used for intra-nasal operations, he perforates the septum opposite the posterior part of the perpendicular plate of the ethmoid. Through this opening, with a pair of punch-forceps, he then removes the posterior extremity of the perpendicular plate, the crest of the sphenoid, and the superior angle of the vomer, with the adjoining part of its posterior border.

Citelli is thus content to make a small window one centimetre square, in the nasal septum, through which, in a second síance, he proceeds to open the sphenoidal sinuses. The opening made in the two sinuses is then enlarged with a chisel or forceps, by opening more freely the sinus corresponding to the nasal fossa through which the operation is conducted, and as much as is necessary of the septum between the two sinuses is removed.

\section{Choice of Operation.}

The different routes which have just been described all present the same drawback, namely, the great distance between their starting-point and the sella turcica at which they terminate. It is for this reason that it is so necessary to illuminate the field of operation, and to select a route which will give a sufficient exposure, while confining the mutilation to a minimum.

It is best not to pronounce a priori in favour of one or other of the rhinological methods. While it must be recognised, on the one hand, that we rhinologists succeed in attaining considerable skill in performing operations in narrow and deep localities, it is no less true that in this case a procedure should be selected which 
gives a sufficient exposure, and which is likely to lead to the best results.

Now, a rhinotomy is not such a difficult or disfiguring operation that it must necessarily be set aside in farour of intra-nasal methods, when it is a question of facilitating an operation as rerious as hypophysectomy. It is thus that the transmaxillo-nasal route, made popular by Moure, has aided to a remarkable degree the performance of certain operations on the ethmoid and on the carum. Why, then, should we judge otherwise when the object is to attack the sphenoid, and to open in the depth of the sinus the -ella turcica, on which the hypophysis rests?

Moreover, in order that a method of hypophysectomy should Ineet with our approval, it must also allow of working in the median line, and an approach to the sphenoidal sinus exactly in the middle and not from one side. It is for this reason that the uriginal method of Hirsch, having the great drawback of necessitating the lateral opening of the sella turcica, was distinctly bad. By straying ever so little from the median line there is a clanger of injuring the carernous sinus or the internal carotid, and the "xtraction of the tumour is rendered almost impossible.

One method, which I hope to re-establish, is the transpalatine method mentioned above. The resection of the vault of the palate and the opening of the sinus through its antero-inferior wall ureatly facilitate access to the sella turcica, which can thus be approached from below upwards, and not by following a parallel Hane, as is often the case in following the nasal route. This way, which, moreover, is much shorter than the nasal route, gives a free 'xposure, and the artificial light, which must alway's be used, can here strike directly on the site of the hypophyseal cell.

It is, in fact, the road which leads directly to the superior wall if the sinus, at least in the generality of cases, and which best lermits finding the bearings.

If a number of median sections or radiographs of the luman head are examined it will be observed that there are cases in which the relations between the sella turcica and the sphenoidal sinus are wch that the nasal route seems unfavourable for hypophysectomr, while the trans-palatine route would lead directly towards the wlla turcica. In others, howerer, serious difficulties would mterfere with the approach to the sella turcica through the palate. it follows that radiography is of the greatest importance here, and that no operation on the hypophysis shonld be undertaken withont having examined heforehand whether the anatomical dispositions 
will permit access to the cell containing the hypophysis by the route which it is proposed to follow.

The trans-palatine route, which constitutes the method of selection when the nasal or intra-nasal route is unsuitable, is hardly mentioned in the works upon the surgery of the hypophysis in spite of the great success which Durante obtained by it. I am convinced that its advantages, in many cases, are not merely theoretical but real. I believe that this route is capable of giving. excellent results; all the more so as it is within the capability of every surgeon, which is not always the case with the intra-nasal ionte.

Quite recently, Prof. Preysing, of Cologne, operated by this method in a case of tumour of the hypophysis, and he was able to verify the relative ease of this mode of operating.

If statistics alone were consulted, the intra-nasal method of Hirsch would appear far superior to all the others. In fact, according to Toupet, who has collected fifty-four cases of extra-cranial hypophysectomy, the nasal route carries a total mortality of 48 per cent., while the intra-nasal method only entails a mortality of 13 per cent. It must, however, be remarked that the intranasal method, which was employed altogether fifteen times, was practised in fourteen of these cases by Hirsch, who had only to register two deaths. But, as Toupet very judiciously remarked, it is illogical to compare the statistics of a single surgeon with the combined statistics of operators of unequal value.

It is to be feared that surgeons less experienced in this peculiarly special branch of surgery, and less skilful than Hirsch, will not have to record such good results, and must also recognist that hypophysectomy by the intra-nasal route is far from being an operation relatively harmless and exempt from difficulties.

However that may be, I asked myself if there was a real advantage in carrying out submucous resection of the septum, which is a long and troublesome operation, and always requires: considerable experience in nasal surgery. Indeed-and upon this point I am in perfect agreement with Citelli and Levinger-I set no reason why Hirsch approaches the sphenoid between the tw" layers of the mucous membrane, since this submucous resection causes as much risk of falling in of the nose as total resection.

The reasons alleged by Hirsch seem to me to be founded on very frail foundations, and I consider that with the method of local anæsthesia by cocaine and adrenalin, hæmorrhage constitute: a factor which need hardly be taken into account. 
The assumption that the danger of infection is reduced to a ninimum in Hirsch's method is a pure hypothesis: for it is evident that in all procedures which follow the inter-nasal route, an aseptic region is placed in communication with a septic one. Nevertheless practice has shown that the fear of meningitis as a sequel to "peration on the hypophysis is more hypothetical than real, since, ont of fifteen operations followed by death, only three cases died from meningitis.

Analogous considerations have led West, as I stated above, to suggest cutting a long rectangular window in the septum: while ('itelli is content to make a little opening near the extremity of the scptum, through which he can penetrate into the sphenoidal -inus.

I have ascertained for myself the difficulty, even on the adaver, of making the small window suggested by Citelli; it is certain that in the living subject considerable difficultios would be met with oftener than we think.

To approach the sphenoid by a very small opening made in the septum seems to me quite illogical and less advisable than the larger opening practised by West. The same conclusion follows (ren from reading the work of Citelli; for he insists, with great truth, on the dangers of opening the sella turcica without following the median line, but at the side. And althongh his experiments were made only on twenty-two bodies, it happened sercral times that he opened the sella laterally; generally on the side "pposite to the nasal fossa through which he operated. For this -erious reason I do not believe that Citelli's method, however simple and rational it seems to he, will be called to a great future. As a rhinological method that of West is preferable although open to *mewhat similar strictures.

The intra-nasal method, which appeared to me the most logical, :1s well as the casiest to execute, and which keeps clear as far as is possible from most of the dangers, is one which consists in the relininary resection of the greater part of the nasal septum. It may perhaps be objected that in making such a complete resection, the operator is deprived of a valuable guide, and that the bearings of the median line may become very difficult to find. On the contrary, by making the resection in the way $I$ am about to "xplain, while leaving the inferior crest of the insertion of the romer, the field of operation is notably enlarged, and the ultimate frocedure in the locality of the sella turcica is rendered easier.

The procedure is as follows: 


\section{Intra-nasal Operation froposed b!y the Author.}

(1) After cocaine anæsthesia and ischæmia by adrenalin, a small double-edged knife is passed into the left nostril, and the septum transfixed from one side to the other, between the columella and the anterior border of the quadrilateral cartilage. The transtixion begins close to the floor, and rises to the level of the insertion of the septum into the bridge of the nose.

(2) 'This incision allows the anterior edge of the quadrilateral cartilage to be made prominent by pushing the detached columellat outwards towards the right nostril.

(3) While an assistant holds the columella aside, the septum in divided from before backwards, a few millimetres above the Hour of the nasal fossa. This can be done with cutting forceps, or even with a special narrow gouge with lateral guards, made on the model of Delie's gouge for the removal of septal spurs. It is sufficient to place the instrument against the anterior edge of the quadrilateral plate a few millimetres above the floor and press firmly upon the handle, in order thus to detach completely the septum below. If the bone offers some resistance, a few blows of the mallet will complete the division. In order to supervise the proper direction of the gouge, parallel to the hard palate, the mallet should be entrusted to an assistant.

(4) The quadrilateral cartilage is divided from front to back 11 a line parallel with the bridge of the nose, but leaving a strip some millimetres in width. The division of the bony septum is then continned either with bone-forceps or the chisel and mallet. following a line parallel to the cribriform plate of the ethmoid. and extending to the body of the sphenoid.

(5) The septum, thus detached above and below is grasped with strong toothed forceps and separated by movements of rotation. All that still remains of the end of the posterior border of the septum, including the crest of the sphenoid, and the superior angle. of the vomer is then removed with cutting forceps.

(6) The resection of the septum having been thus carried ont and all bleeding stopped, Killian's speculum is passed into the left nostril and opened widely so as to crush the middle turbinals, which are in the way on each side, and the lateral masses of the ethmoil If necessary, parts which might be obstacles to the opening of the sphenoidal sinus should be resected.

(7) 'The opening of the sphenoidal sinus and the trephining of the sella turcica is easily carried out between the two blades of th. 
speculum, which the assistant holds exactly in the middle line. The inferior median crest, which the operator has taken care to leave, here serves as an excellent guide-line.

There are certain points in this operation upon which I should like to insist in conclusion. The intra-nasal ronte, as I have indi(ated it, is preferable to the others for the following reasons:

(1) The displacement outwards of the columnar cartilage allows an easy approach to the sphenoidal sinus, and free access to the median part of its anterior wall. It leads directly to the sphenoidal inus, and does not, like the other routes, follow a more or less (b)lique line.

(2) It does not demand, like the method of Hirsch, a submucous resection, which is generally long and tedious. Resection of the nasal septum, without preserving the mucous layers, is a relatively simple procedure, within the capability of every rhinologist, and which can be performed in a very short time.

(3) By leaving the dorsal framework the nose will show no tendency to collapse. Resection of the septum, as I understand it, is an ideal operation from an æsthetic aspect.

(4) Although the two nasal passages are converted into one avity more than double as wide, the operation has the great advantage over most procedures by the external route, that it leaves ill place as far as possible the turbinals and the ethmoid system.

To surgeons who do not care to adopt the intra-nasal route, because they have not acquired the manual dexterity to render its performance easy, I recommend the plan of making a wide opening into the nose before resecting the septum.

The operation which I prefer in this case, both from the æsthetic point of view and because of the rapidity with which it can be arried out, is paramedian vertical rhinotomy, of which the following is the technique.

With strong straight scissors, one blade of which is introduced :nto the left nostril, the skin and subjacent cartilage are divided, as ar as the nasal bone, and the incision is prolonged with a scalpel "II the bone up to the root of the nose.

The flap is dissected off, freed from its bony attachments, and arned to the side; and, in order to enlarge the orifice of entry into . he nasal fossa, parts of the nasal bone and of the ascending process it the superior maxilla are resected.

The resection of the cartilaginous septum, followed by crushing ibstructing turbinals, is then carried out through the operationround with the greatest ease. 
This method, which reduces the mutilation to a minimum, giver an exposure sufficient to render all the later stages on the sphenoidal sinus and the sella turcica convenient and easy. By this route the sphenoidal sinus is reached, not by following the roof of the nasal fossæ, as in the operations of Schloffer and others, but along a median plane, slightly oblique from below upwards. I think that this route is quite as good as that named by Giordano the transethmoidal ronte, which requires the complete resection of the ethmoid, and an eracuation of the contents of the nasal carity-a mutilation very often uscless.

\section{Conclusions.}

(1) Before operating on the hypophysis it is important th. ascertain on a successful radiograph that the anatomical relation: between the hypophysis and the sphenoidal sinus do not contraindicate the route which it is proposed to follow.

(2) The transpalatine, being the shortest and most direct route, deserves to take an important place in the surgery of the hypophysis.

(3) Operations by the nasal or intra-nasal route very often onl! allow an incomplete eracuation or curettage of the hypophyseat cell.

(4) The intra-nasal route is the most conservative, but is onl! capable of affording good results in the hands of rhinologists.

(5) In the methods of West and Citelli there is a risk of openin:the sella turcica, not in the median line but on one side, which might be productive of disasters.

(6) The method of Hirsch, which includes submucous resection: of the septum, is long and fatiguing, and demands unusuat dexterity. Total resection of the nasal septum, with preservation th the dorsal arch, is superior to it from an asthetic point of view, an: also in the time taken in performing it.

(7) Resection of the septum may be preceded with advantage b! a wide opening into the nasal fossa. Tertical paramedian: rhinotomy is the operation of choice. 